\title{
A Regional Semi-Distributed Streamflow Model Using Deep Learning
}

\author{
Zhongrun Xiang ${ }^{1,}{ }^{*}$, Ibrahim Demir $^{1}$, Ricardo Mantilla ${ }^{1}$, Witold F. Krajewski ${ }^{1}$ \\ ${ }^{1}$ Civil and Environmental Engineering, University of Iowa \\ *Corresponding Author: zhongrun-xiang@uiowa.edu
}

\begin{abstract}
Recent studies have shown that deep learning models in hydrological applications significantly improved streamflow predictions at multiple stations compared to traditional machine learning approaches. However, most studies lack generalization; i.e. researchers are training separate models for each location. The spatial and temporal generalization ability of deep learning models in hydrology that can be gained by training a single model for multiple stations is evaluated in this study. We developed a generalized model with a multi-site structure for hourly streamflow hindcasts on 125 USGS gauges. Considering watershed-scale features including drainage area, time of concentration, slope, and soil types, the proposed models have acceptable performance and slightly higher median NSE value than training individual models for each USGS station. Furthermore, we showed that the trained generalized model can be applied to any new gauge in the state of Iowa that was not used in the training set with acceptable accuracy. This study demonstrates the potential of deep learning studies in hydrology where more domain knowledge and physical features can support further generalization.
\end{abstract}

Key Words: Rainfall-runoff modeling; deep learning; general semi-distributed model; streamflow hindcasting; data integration modeling

This manuscript is an EarthArXiv preprint and has been submitted for possible publication in the Journal of Hydrology. Please note that this has not been peer-reviewed before and is currently undergoing peer-review for the first time. Subsequent versions of this manuscript may have slightly different content. If accepted, the final version of this manuscript will be available via the 'Peer-reviewed publication DOI' link on this webpage. Please feel free to contact the authors; we welcome feedback. 


\section{Introduction}

Increases in streamflow due to heavy precipitation is the main driving force of flooding, which has become an ongoing concern in Iowa over the past three decades. In particular, the severe flooding in 2008 (e.g. Smith et al., 2012; Krajewski and Mantilla, 2010) gave impetus to many new developments. In 2009 the state legislators established the Iowa Flood Center (Krajewski et al. 2017), that in turn has made significant improvements in streamflow monitoring (Kruger et al. 2016; Quintero et al. 2021), development of flood inundation maps (Gilles et al. 2011), streamflow forecasting (Krajewski et al. 2017; Quintero et al. 2020a,b), and communication and outreach to the public (e.g. Demir and Krajewski, 2012). Additional relevant advances are documented in Seo and Krajewski (2020), Ha et al. (2020), Ghimire et al. (2018), and Perez et al. (2018). Many other technological developments have been demonstrated as concepts or prototypes (Sermet et al. 2020; Demir and Szczepanek 2017; Sermet and Demir 2019, Yildirim and Demir, 2019; Xu et al., 2020).

These above developments provide a stage for exploring the latest methods of Artificial Intelligence to improve hydrologic modeling, analysis and forecasting (Agliamzanov et al., 2020; Xiang et al., 2020). While many hydrologic models have been developed over the past 50 years, the challenge of providing streamflow forecasts accurately, efficiently and everywhere at all times remains. Several studies have applied deep learning in water resources fields, including surface water quality (Hu et al., 2019; Zhou, 2020), streamflow forecasting (Feng et al., 2020; Li et al., 2020; Qian et al., 2020; Sarkar et al., 2020; Van et al., 2020; Yue et al., 2020), soil moisture (Fang and Shen, 2020), groundwater (Wang et al., 2020; Yu et al., 2020), hydrometeorology (Chen et al., 2020; Lee et al., 2020), and water management (Liu et al., 2019). Recent studies (Chang et al., 2015; Granata et al., 2016; Faruk, 2010; Sit and Demir, 2019) have shown that many machine learning and deep learning models could be valuable in streamflow forecasting. 
However, these studies have not emphasized the inclusion of physical watershed characteristics in the models. Recent studies (Chu et al., 2020; Kratzert et al., 2018; Ni et al., 2020; Xiang et al., 2020) have applied deep learning models to multiple watersheds while using a separate model for each watershed or gauge. While developing one model for each watershed improves accuracy of prediction, it is inefficient and difficult to apply on a larger scale. Kratzert et al. (2018) tested deep learning models trained on multiple gauges in a hydrologic unit; this study concluded that a generalized model trained on multiple gauges may perform better than training one model for each watershed if there is a strong correlation in their discharge behavior.

On the other hand, regional modeling has been thoroughly studied in hydrology. As shown in the review by Razavi and Coulibaly (2013), six different approaches can be used to predict ungauged basins, including the spatial distance approach, physical similarity approach, hydrological similarity approach, arithmetic mean method, scaling relationships, and linear and nonlinear regression-based methods. More recently, machine learning studies have applied classic models such as support vector machine (Yahya et al., 2019) and random forests (Prieto et al., 2019) to ungauged watersheds using various regionalization methods. Each of these methods has limitations, thus, it remains an important challenge in hydrology (Sivapalan et al., 2003). As proposed by Kokkonen et al. (2003), the generalized model requires incorporating the physical features of the watershed, which can be categorized in two groups: (1) physiographic information (i.e., watershed area, and slope); and (2) meteorological features (i.e., mean rainfall, temperature) (Razavi and Coulibaly, 2013). These features can easily be included as input and applied to machine learning and deep learning models.

Kratzert et al. (2019) designed a new deep learning layer that allows for learning watershed similarities as a feature layer and trained a single model on 531 basins in the 
CAMELS dataset (Addor et al., 2017). The results outperformed the models trained on a single basin. This confirmed that machine learning models can learn regional hydrological behaviors. This provides the impetus to develop a single generalized model for all watersheds rather than training one model for each watershed. However, there are several limitations in such generalized approaches. The first is the requirement for a large amount of data that should be used at the community level for model benchmarks (Ebert-Uphoff et al., 2017). Some watershed features (i.e., depth to bedrock) may not be available in other datasets. In addition, the selected watersheds in Kratzert's study are less than 2,000 km². However, many USGS gauges (i.e., 51 out of 125 selected USGS streamflow gauges in Iowa) are monitoring watersheds larger than $2,000 \mathrm{~km}^{2}$. The behavior of streamflow fluctuations in small and large watersheds are different in terms of the time scale of the variability. Predicting the value of streamflow in a large $\left(10,000 \mathrm{~km}^{2}\right)$ basin in the next hour is an easy task, most likely it's the same value that is being currently observed, even if it's raining, on the other hand, predicting the value of streamflow in a small $\left(10 \mathrm{~km}^{2}\right)$ basin in the next hour while it's still raining can be a major challenge because the rainfall-runoff processes occur on the same time scale of the streamflow fluctuations. These limitations could restrict the applicability of the regional learning approach using deep learning.

Xiang and Demir (2020) proposed a deep learning based semi-distributed hydrological model named the Neural Runoff Model (NRM) to predict the next 120 hours on gauged watersheds; using this approach 125 NRM models have been trained on 125 USGS gauges in Iowa with better performance than traditional machine learning models. Xiang and Demir (2020) averaged prediction performance indexes for fix lead times (e.g. 5-hours), however that can lead to misinterpretation of the actual performance of the model. The mix of how many large watersheds vs. small watersheds can influence the value of the average. This 
is a limitation on evaluation that is present in other studies as well (Kratzert et al., 2018; Kratzert et al., 2019). We address this limitation and others in this study.

In particular, in this study, the regional generalization is considered in the deep learning-based streamflow modeling. We create a generalized streamflow simulation model for different watersheds using physical features with standard deep learning architectures, to illustrate how the generalized model performs compared to the one model for each watershed approach in streamflow hindcasting across scales. In addition, we tested the generalized model on additional watersheds outside of the training dataset (e.g., ungauged watersheds) to evaluate the transferability of the final models. Our study is limited to hindcasting, where "future rainfall" is known perfectly. Future work, on forecasting, and other issues are also outlined in the conclusions of this work.

\section{Methods}

\subsection{NRM-Generalized and NRM-Generalized-Distributed}

We investigate two generalized model architectures, the NRM-Generalized and the NRMGeneralized-Distributed. These two model architectures were developed and improved upon based on previous work of NRM based on an encoder-decoder structured recurrent neural network (Xiang and Demir, 2020). NRM-Generalized is a lumped model that uses watershedscale time-series data and physical features as input to simultaneously predict streamflow in all the catchments. The structure of NRM-Generalized proposed in this study is shown in Fig.

1. This regional generalized model includes physical characteristics such as watershed area, soil type, slope, etc., which are not considered in the original NRM because each model is trained independently and thus watershed features are constant for each NRM. However, these features are needed to characterize different watersheds for the development of the generalized model for multiple watersheds. 
The NRM-Generalized model considered four physical features for each watershed: the average slope, area, time of concentration $\left(\mathrm{T}_{\mathrm{c}}\right)$ based on the longest path, and the proportion of the 12 soil types in the watersheds. All these physical features are assumed to be constant over time. These data, combined with hourly precipitation (Seo et al., 2019), hourly streamflow, and monthly evapotranspiration, are used as the input in this study. All these data are available from public sources; details, including pretreatment of these data, are shown in Table 1 . The composition ratios have 12 values for different soil types. Thus, there are 18 input features for NRM-Generalized.

In the watershed-level NRM model, we used the variance unexplained (FVU, Equation 1) as the loss function, which minimized the error and maximized the NashSutcliffe model efficiency coefficient NSE. Although this is an efficient and dimensionless loss function that has already been tested in previous studies for a single watershed, this function can cause bias based on watershed size. This occurs because large watersheds normally have higher streamflow values where FVU and NSE are sensitive. The loss function designed for the NRM-Generalized is shown in Equation 2, which is calculated based on different timesteps, in one training instance before calculation of the watershed average. The designed loss function ensures that all variant watershed sizes and flow rates are taken into account in the optimization. 


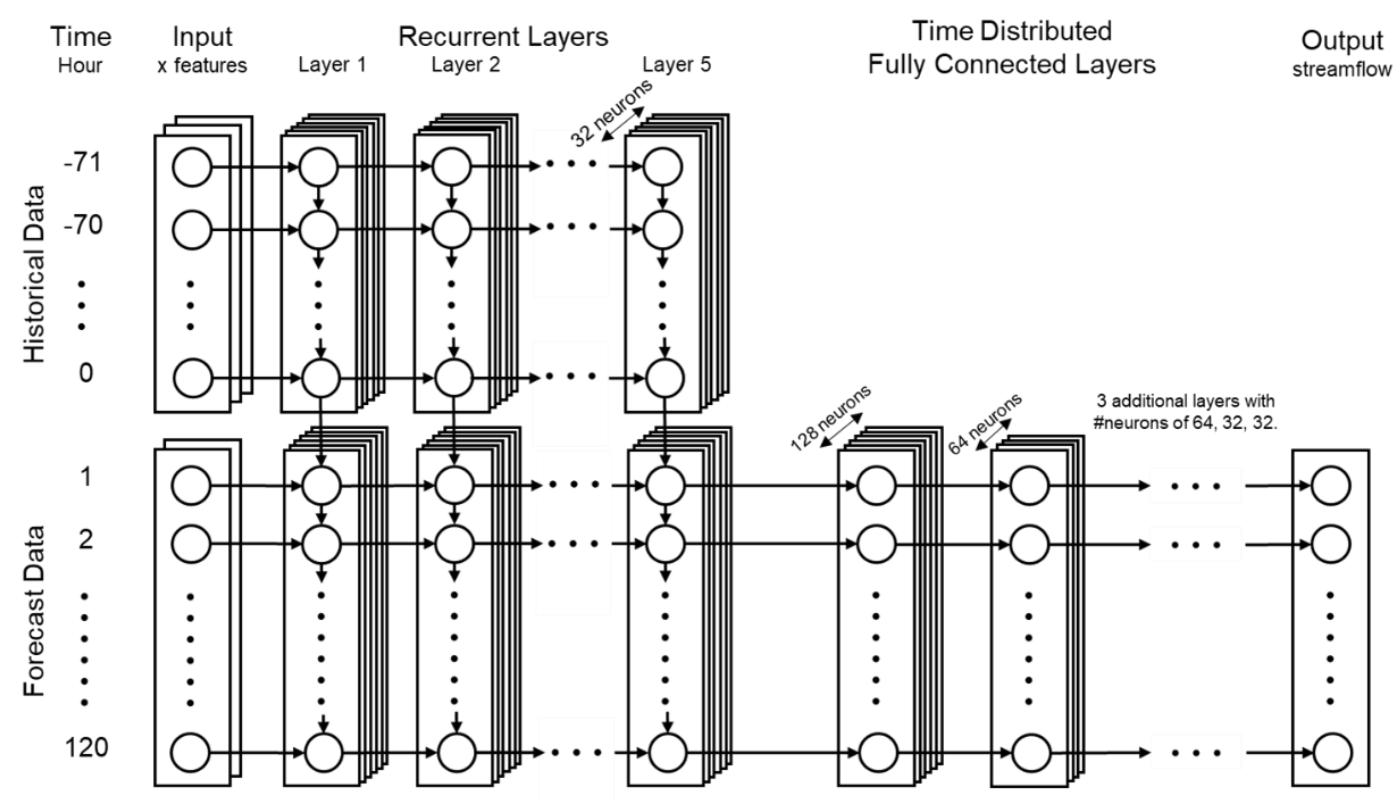

Figure 1. NRM-Generalized Model structure. The data required for this study includes the watershed area, $\mathrm{T}_{\mathrm{c}}$, watershed average slope, soil types, hourly precipitation, ET, and streamflow rate. For each instance, the streamflow rate for the next 120 hours is the model output, and the rest of the features are the model input.

Table 1. Data used in the development of NRM-Generalized.

\begin{tabular}{cccccc}
\hline Input Data & Data Type & Source & $\begin{array}{c}\text { Spatial } \\
\text { Resolution }\end{array}$ & $\begin{array}{c}\text { Temporal } \\
\text { Resolution }\end{array}$ & Pretreatment \\
\hline Precipitation & $\begin{array}{c}\text { Stage IV multi-sensor } \\
\text { measurement (Lin, 2011) }\end{array}$ & NOAA & 4km grid & hourly & $\begin{array}{c}\text { Area-weighted, 6-hr moving } \\
\text { average for each watershed }\end{array}$ \\
\hline Streamflow & $\begin{array}{c}\text { USGS gage } \\
\text { measurement }\end{array}$ & USGS & Gauge-based & $5-60$ mins & Aggregate to hourly \\
\hline ET & $\begin{array}{c}\text { Empirical historical data } \\
\text { (Krajewski et al., 2017) }\end{array}$ & IFC & State-based & monthly & $\begin{array}{c}\text { Repeat each station and } \\
\text { each hour }\end{array}$ \\
\hline Slope & Hillslope data & IFC & Hillslope-based & constant & $\begin{array}{c}\text { Median slope of each } \\
\text { watershed, repeat to hourly }\end{array}$ \\
\hline Area & GIS data & IFC & Gauge-based & constant & Repeat to hourly \\
\hline $\mathrm{T}_{\mathrm{c}}$ & GIS data & IFC & Gauge-based & constant & Repeat to hourly \\
\hline $\begin{array}{c}\text { Composition } \\
\text { ratio of soil types }\end{array}$ & Soil data & IFC & 0.5-degree grid & constant & Repeat to hourly \\
\hline
\end{tabular}

$$
\begin{aligned}
& \mathrm{FVU}=1-\mathrm{NSE}=\frac{\sum_{i=1}^{m}\left(Y_{i}-\hat{\mathrm{Y}}_{i}\right)^{2}}{\sum_{i=1}^{m}\left(Y_{i}-\overline{\mathrm{Y}}\right)^{2}} \\
& \text { Loss Function }=\frac{\sum_{i=1}^{m} \frac{\sum_{j=1}^{n}\left(Y_{i, j}-\hat{\mathrm{Y}}_{i, j}\right)^{2}}{\sum_{j=1}^{n}\left(Y_{i, j}-\overline{\mathrm{Y}}_{j}\right)^{2}}}{m}
\end{aligned}
$$


where: $\mathrm{Y}_{i, j}$ is the observation at the time step $i$ and sample instance $j ; \hat{\mathrm{Y}}_{i, j}$ is the model result at the time step $i$ and sample instance $j$; $\bar{Y}_{j}$ is the mean of all observations among time steps in one sample instance; $m$ is the total number of the sample instances; and $n$ is the total number of time steps. In this study, the $n$ prediction timestep setting is $120 ; m$ is the batch size setting of 32 .

To better model the streamflow, we applied a semi-distributed structure based on the NRM-Generalized and named this structure NRM-Generalized-Distributed. NRM-

Generalized-Distributed is a semi-distributed model and considers each gauged basin as a sub-basin for large watersheds, and all the time-series data and physical features are based on the sub-basin only. In the previous study, NRM-Distributed models (with semi-distributed model structure) were trained one by one, sequentially from upstream to downstream. However, this is impossible in a generalized model because all watersheds must be trained simultaneously in one model. Thus, the upstream-downstream relationship is constructed, and it serves as the input in the training. Table 2 shows sample input features for gauge 565 and its downstream gauge 566 in each timestep before min-max scaling in models NRM, NRMGeneralized, and NRM-Generalized-Distributed. For NRM, there are only 3 input features, while the input increased to 18 and 19 for NRM-Generalized and NRM-GeneralizedDistributed, respectively. NRM-Generalized-Distributed has additional features of the upstream streamflow. For gauges with no upstream gauges (as for gauge 565), the upstream flow rate is set as 0 . In addition, since gauge 566 is the downstream of gauge 565, the area, $\mathrm{T}_{\mathrm{c}}$, slope, soil type proportions, and precipitation of gauge 566 are calculated from the subwatershed, excluding the watershed of gauge 565. 
Table 2. Example input dataset of stream ID and input features in different models.

\begin{tabular}{|c|c|c|c|c|c|c|c|c|c|c|}
\hline & $\begin{array}{l}\text { Gauge } \\
\text { ID }\end{array}$ & $\begin{array}{l}\text { Area } \\
\left(\mathrm{km}^{2}\right)\end{array}$ & $\begin{array}{l}\mathrm{T}_{\mathrm{c}} \\
\text { (hr.) }\end{array}$ & $\begin{array}{l}\text { Slope } \\
(\%)\end{array}$ & $\begin{array}{l}\text { Loam } \\
(\%)\end{array}$ & $\begin{array}{l}\text { Other Soil } \\
\text { Types }(\%)\end{array}$ & $\begin{array}{c}\mathrm{ET}(\mathrm{mm} / \\
\text { mon) }\end{array}$ & $\begin{array}{l}\text { Precip. } \\
\left(\mathrm{m}^{3} / \mathrm{s}\right)\end{array}$ & $\begin{array}{l}\text { Upstream Stream } \\
\text { flow }\left(\mathrm{m}^{3} / \mathrm{s}\right)\end{array}$ & $\begin{array}{c}\text { Streamflow } \\
\left(\mathrm{m}^{3} / \mathrm{s}\right)\end{array}$ \\
\hline \multirow{6}{*}{$\sum_{z}$} & 565 & -- & -- & -- & -- & -- & 20 & 5.598 & \multirow{6}{*}{ Not Available } & 1.031 \\
\hline & 565 & -- & -- & -- & -- & -- & 20 & 6.458 & & 1.031 \\
\hline & $\ldots$ & $\ldots$ & $\ldots$ & $\ldots$ & $\ldots$ & $\ldots$ & $\ldots$ & $\ldots$ & & $\ldots$ \\
\hline & 566 & -- & -- & -- & -- & -- & 20 & 5.602 & & 1.393 \\
\hline & 566 & -- & -- & -- & -- & -- & 20 & 6.551 & & 1.405 \\
\hline & $\ldots$ & $\ldots$ & $\ldots$ & $\ldots$ & $\ldots$ & $\ldots$ & $\ldots$ & $\ldots$ & & $\ldots$ \\
\hline \multirow{6}{*}{ 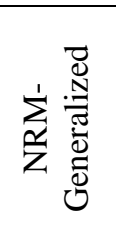 } & 565 & 835 & 37 & 1.57 & 40.1 & $\ldots$ & 20 & 5.598 & \multirow{6}{*}{ Not Available } & 1.031 \\
\hline & 565 & 835 & 37 & 1.57 & 40.1 & $\ldots$ & 20 & 6.458 & & 1.031 \\
\hline & $\ldots$ & $\ldots$ & $\ldots$ & $\ldots$ & $\ldots$ & $\ldots$ & $\ldots$ & $\ldots$ & & $\ldots$ \\
\hline & 566 & 937 & 44 & 1.56 & 42.8 & $\ldots$ & 20 & 5.602 & & 1.393 \\
\hline & 566 & 937 & 44 & 1.56 & 42.8 & $\ldots$ & 20 & 6.551 & & 1.405 \\
\hline & 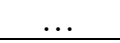 & $\ldots$ & $\ldots$ & $\ldots$ & $\ldots$ & $\ldots$ & $\ldots$ & $\ldots$ & & $\ldots$ \\
\hline \multirow{6}{*}{ 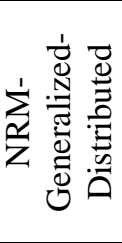 } & 565 & 835 & 37 & 1.57 & 40.1 & $\ldots$ & 20 & 5.598 & $\mathbf{0}$ & 1.031 \\
\hline & 565 & 835 & 37 & 1.57 & 40.1 & $\ldots$ & 20 & 6.458 & $\mathbf{0}$ & 1.031 \\
\hline & $\ldots$ & $\ldots$ & $\ldots$ & $\ldots$ & $\ldots$ & $\ldots$ & $\ldots$ & $\ldots$ & $\ldots$ & $\ldots$ \\
\hline & 566 & 102 & 7 & 1.48 & 65.1 & $\ldots$ & 20 & 0.004 & 1.031 & 1.393 \\
\hline & 566 & 102 & 7 & 1.48 & 65.1 & $\ldots$ & 20 & 0.093 & 1.031 & 1.405 \\
\hline & $\ldots$ & $\ldots$ & $\ldots$ & $\ldots$ & $\ldots$ & $\ldots$ & $\ldots$ & $\ldots$ & $\ldots$ & $\ldots$ \\
\hline
\end{tabular}

\subsection{Model Settings and Evaluation}

Using the upstream-downstream relation, two separate datasets were created with 18 and 19 input features as shown in Table 2, with input from 125 USGS gauges for NRM-Generalized and NRM-Generalized-Distributed models. Three different subsets (training, validation, and test datasets) are created from the data in the water years 2014-2017, 2012-2013, and 2018, respectively. We used the training and validation datasets to calibrate the models. The test dataset was used for the final evaluation. All analyses in section 3 results are based on the test dataset. The statistics of the features among these watersheds are shown in Table 3.

After removing missing data for 125 USGS streamflow gauges, a total of 2,808,832 instances remained in the training dataset; 1,552,150 instances in the validation dataset; and 866,664 instances in the test dataset. These datasets were split by the gauges based on the tests. This study used a small batch size of 32 that randomly trained 32 instances at a time. The optimizer is RMSprop, which is known to perform well on time-series models. Because there were 12 more inputs from 4 features, a small learning rate of 0.00003 was used for the optimizer. All other settings in this study were the same as were used in the NRM model to 
maintain the consistency for our comparison. All these settings were implemented by the Keras library in Python3 with the Tensorflow backend using NVIDIA Titan V GPU.

Table 3. Statistics of the physical features in different models used in this study. In distributed structures, only the sub-watersheds are considered.

\begin{tabular}{|c|c|c|c|c|c|c|}
\hline & & Upstream & $\begin{array}{c}\text { Downstream } \\
\text { Lumped }\end{array}$ & $\begin{array}{c}\text { Downstream } \\
\text { Semi-Distributed }\end{array}$ & $\begin{array}{c}\text { All } \\
\text { Lumped }\end{array}$ & $\begin{array}{c}\text { All } \\
\text { Semi-Distributed }\end{array}$ \\
\hline \multirow{4}{*}{$\begin{array}{l}\text { Area } \\
\left(\mathrm{km}^{2}\right)\end{array}$} & Min & 6 & 206 & 72 & 6 & 6 \\
\hline & Max & 3,772 & 31,828 & 10,690 & 31,828 & 10,690 \\
\hline & Median & 786 & 4,247 & 1,394 & 1,675 & 947 \\
\hline & SD & 687 & 8,697 & 2,189 & 7,264 & 1,715 \\
\hline \multirow{4}{*}{$\mathrm{T}_{\mathrm{c}}$ (hour) } & Min & 2 & 17 & 1 & 2 & 1 \\
\hline & Max & 101 & 315 & 118 & 315 & 118 \\
\hline & Median & 32 & 99 & 21 & 53 & 26 \\
\hline & SD & 18 & 71 & 22 & 68 & 21 \\
\hline \multirow{4}{*}{ Slope } & Min & $0.4 \%$ & $1.0 \%$ & $1.0 \%$ & $0.4 \%$ & $0.4 \%$ \\
\hline & $\operatorname{Max}$ & $4.3 \%$ & $3.8 \%$ & $5.7 \%$ & $4.3 \%$ & $5.7 \%$ \\
\hline & Median & $1.7 \%$ & $1.8 \%$ & $2.2 \%$ & $1.8 \%$ & $2.0 \%$ \\
\hline & SD & $0.9 \%$ & $0.7 \%$ & $1.0 \%$ & $0.8 \%$ & $1.0 \%$ \\
\hline \multirow{4}{*}{ Loam } & Min & $0 \%$ & $0 \%$ & $0 \%$ & $0 \%$ & $0 \%$ \\
\hline & Max & $98 \%$ & $95 \%$ & $94 \%$ & $98 \%$ & $98 \%$ \\
\hline & Median & $14 \%$ & $36 \%$ & $26 \%$ & $33 \%$ & $24 \%$ \\
\hline & SD & $29 \%$ & $24 \%$ & $27 \%$ & $28 \%$ & $28 \%$ \\
\hline \multirow{4}{*}{ Silt } & Min & $0 \%$ & $0 \%$ & $0 \%$ & $0 \%$ & $0 \%$ \\
\hline & $\operatorname{Max}$ & $100 \%$ & $84 \%$ & $99 \%$ & $100 \%$ & $100 \%$ \\
\hline & Median & $31 \%$ & $15 \%$ & $39 \%$ & $21 \%$ & $38 \%$ \\
\hline & SD & $36 \%$ & $22 \%$ & $36 \%$ & $30 \%$ & $35 \%$ \\
\hline \multirow{4}{*}{$\begin{array}{c}\text { Sandy } \\
\text { clay loam }\end{array}$} & Min & $0 \%$ & $0 \%$ & $0 \%$ & $0 \%$ & $0 \%$ \\
\hline & Max & $84 \%$ & $78 \%$ & $74 \%$ & $84 \%$ & $84 \%$ \\
\hline & Median & $0 \%$ & $12 \%$ & $0 \%$ & $4 \%$ & $0 \%$ \\
\hline & SD & $23 \%$ & $24 \%$ & $23 \%$ & $24 \%$ & $23 \%$ \\
\hline \multirow{4}{*}{$\begin{array}{l}\text { Silty clay } \\
\text { loam }\end{array}$} & Min & $0 \%$ & $0 \%$ & $0 \%$ & $0 \%$ & $0 \%$ \\
\hline & $\operatorname{Max}$ & $93 \%$ & $88 \%$ & $85 \%$ & $93 \%$ & $93 \%$ \\
\hline & Median & $9 \%$ & $7 \%$ & $4 \%$ & $7 \%$ & $6 \%$ \\
\hline & SD & $26 \%$ & $19 \%$ & $20 \%$ & $23 \%$ & $24 \%$ \\
\hline
\end{tabular}

We used NSE (Equation 3) and KGE (Equation 4) as the performance statistics in this study (Gupta et al., 2009). These dimensionless metrics are widely used for hydrological modeling; the equations are shown below. Because both metrics are sensitive to extreme values in the test year, NSE and KGE were calculated using two different values: the streamflow values in $\mathrm{m}^{3} / \mathrm{s}$, and the streamflow quantiles in the test year. 


$$
\begin{aligned}
& \mathrm{NSE}=1-\frac{\sum_{i=1}^{n}\left(Y_{i}-\hat{\mathrm{Y}}_{i}\right)^{2}}{\sum_{i=1}^{n}\left(Y_{i}-\bar{Y}\right)^{2}} \\
& \mathrm{KGE}=1-\sqrt{(\mathrm{r}-1)^{2}+\left(\frac{\sigma_{\hat{\mathrm{Y}}_{i}}}{\sigma_{\mathrm{Y}_{\mathrm{i}}}}-1\right)^{2}+\left(\frac{\mu_{\hat{\mathrm{Y}}_{i}}}{\overline{\mathrm{Y}}}-1\right)^{2}}
\end{aligned}
$$

where: $\mathrm{Y}_{i}$ is the observation at the time $i$; $\hat{\mathrm{Y}}_{i}$ is the model result at the time $i$; $\overline{\mathrm{Y}}_{i}$ is the mean of all observations; $n$ is the total number of observations; $r$ is the Pearson correlation coefficient; $\sigma$ is the standard deviation; and $\mu$ is the mean.

The goal in this study is to simulate the hourly streamflow at multiple watersheds using one model for multiple hours; it is obvious that longer lead times are harder to predict. Thus, we conducted a longitudinal comparison of the model performances (NSE and KGE) at the longest lead time among different watersheds. However, the time of concentration for different watersheds vary widely, and it is not fair to compare the predictions at the same lead time among different watersheds. Thus, a dimensionless time axis was used in the longitudinal comparison of the model performances in the time series. In this study, the dimensionless time axis was defined as the ratio of the lead time over the concentration-time. Although it may seem fair to compare the prediction skill for a fix lead time, as previous studies did (Xiang et al., 2020; Xiang and Demir, 2020), the prediction performance of different watersheds was significantly affected by their size and concentration time, and the statistics based on lead time. It has been demonstrated in some studies that the prediction skill of temporal persistence as a benchmark method is sensitive to the lead time and concentration time, and the temporal persistence offers good performance especially for larger basins (Ghimire and Krajewski, 2020). Especially in the streamflow modeling task in this study, the prediction of a small watershed with short concentration time was much harder than the prediction of a large watershed with a longer concentration time. 


\subsection{Case Studies}

We carried out four tests shown in Table 4 to develop and evaluate the regional generalized models. The first test used 62 independent upstream gauges, the most upstream stations in Iowa, to develop the generalized model. Although a total of 125 USGS streamflow gauges exist in Iowa, as shown in Fig. 2, we rule out correlated gauges in this test because downstream gauges are measuring the watersheds with overlapped areas. In this test, only 62 upstream gauges were used to develop and evaluate the model. This is a naïve test to apply the proposed NRM-Generalized model on independent upstream gauges for evaluating the model effectiveness.

In the second test, we evaluated the spatial generalization capability of this model on untrained watersheds. Specifically, we trained a new NRM-Generalized model with 42 randomly selected upstream watersheds selected from 62 upstream watersheds. We applied the model to the 42 trained gauges as well as the 20 untrained upstream gauges. We sorted the 62 independent upstream watersheds by area. Every third watershed was marked (i.e., watersheds No. 3, 6, 9, etc., by area), and the 42 unmarked upstream watersheds were used for training in this test. Thus, 20 untrained upstream gauges were used to evaluate the generalizability of the model to a completely different watershed set. We also applied the trained model to 18 additional watersheds located downstream from the 42 trained watersheds to evaluate the generalizability of the extension. In this test, we used only the gauges with green markers to develop the model, as shown in Fig. 2. They were applied to both upstream gauges in green and downstream gauges in red.

In the third test, we conducted an ablation study to learn if all four physical features are necessary to develop the generalized model. The study helped us understand the importance and contribution of physical features on the modeling. In this test, only 62 upstream gauges shown in Fig. 2 were considered in training and evaluation. 
In the last test, we implemented NRM-Generalized-Distributed approach to two new regional models for 63 downstream watersheds and all watersheds with 125 USGS gauges in Iowa with and without distributed structure. As shown in Table 4, we trained four models in this test. The downstream models were trained on 63 gauges; the overall models were trained on 125 gauges. Furthermore, we applied the distributed structure to the generalized models. In the distributed models, the observed upstream streamflow in the future were used in the training, and the model output of upstream gauges were used in the test for evaluation. In the end, we evaluated our best models for 125 watersheds in this test for our final evaluation and visualization.

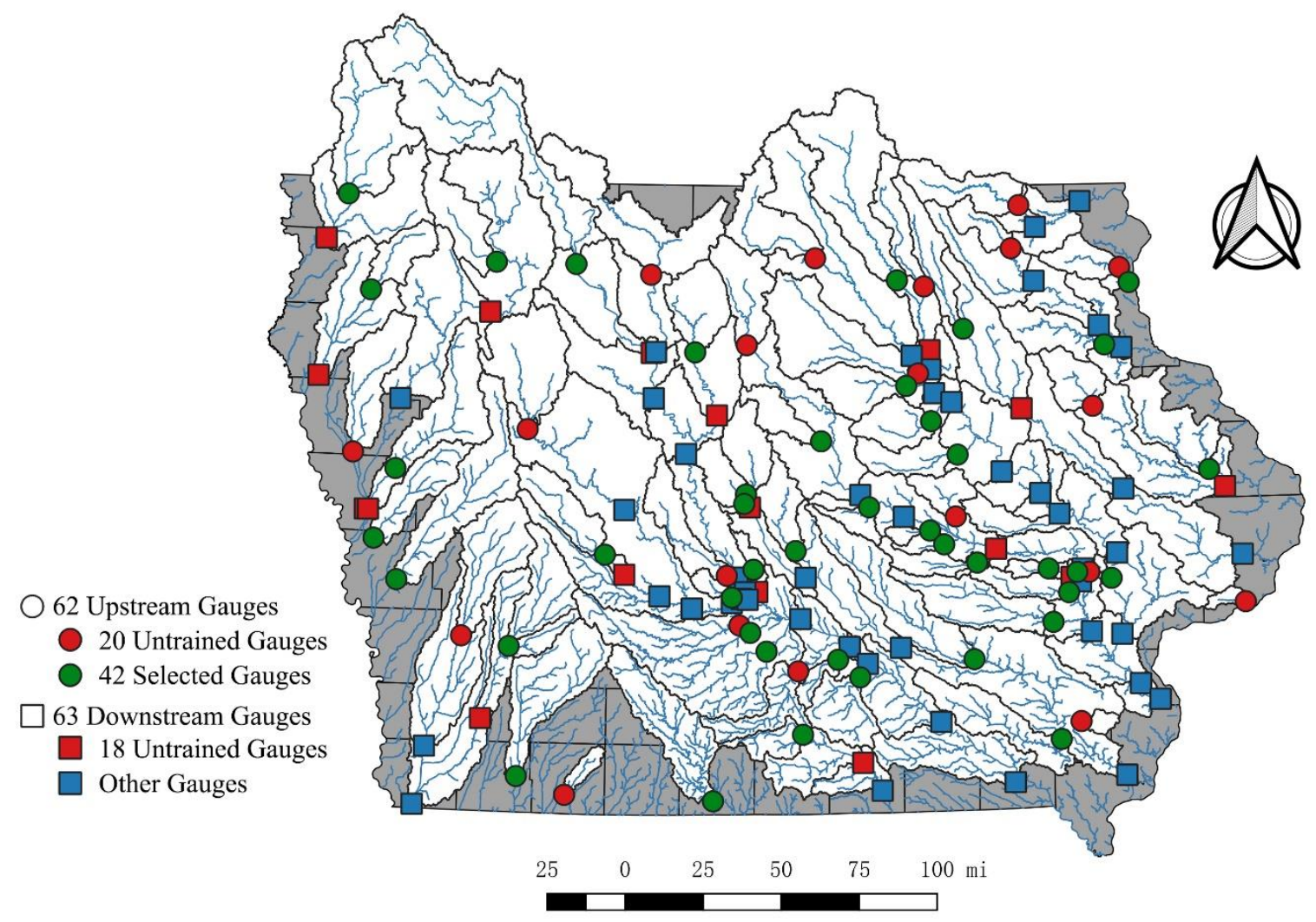

Figure 2. The distribution of USGS gauges in Iowa.

\subsection{Performance Benchmarks}

One reference used in this study is temporal persistence (or autocorrelation) in time. As a benchmark in hydrology, persistence forecast is also known as a hard to beat model for large 
watersheds at short to medium forecast range. Many studies suggest that persistence can be an alternative for evaluating future estimates of streamflow at short to medium range (Ghimire and Krajewski, 2020; Krajewski et al. 2020).

Because this study aims to explore potential generalization ability, its main benchmarks are the watershed-based model NRM and NRM-Distributed (Xiang and Demir, 2020). NRM and NRM-Distributed are watershed-based models that train and test on each gauge separately. Thus, comparing the NRM-Generalized model results to NRM is like comparing one model to 125 different models.

The third baseline is the NRM-Generalized-Baseline, which considers time-series features, including the precipitation, ET, and streamflow from all watersheds, but not watershed level features. The features of this model are shown in Table 4 Test 1 . We do not compare to other machine learning models such as support vector machine or random forest because the NRM and NRM-Distributed models have shown better results compared to deep learning models in previous studies using the same dataset. 
Table 4. Model settings and input data selection in each test in the study.

\begin{tabular}{|c|c|c|c|c|c|c|c|c|c|c|c|c|}
\hline & Model Name & $\begin{array}{c}\text { Train } \\
\text { Watersheds }\end{array}$ & $\begin{array}{c}\text { Evaluation } \\
\text { Watersheds }\end{array}$ & $\begin{array}{l}\text { Number } \\
\text { of Models }\end{array}$ & Precip. & ET & Streamflow & Slope & Area & $\mathbf{T}_{\mathbf{c}}$ & Soil & Upstream \\
\hline \multirow{3}{*}{ Baseline } & Temporal Persistence & -- & $\begin{array}{c}125 \text { All } \\
\text { Watersheds }\end{array}$ & 1 & -- & -- & $\sqrt{ }$ & -- & -- & -- & -- & -- \\
\hline & $\begin{array}{l}\text { NRM (Xiang \& Demir, } \\
\text { 2020) }\end{array}$ & \multicolumn{2}{|c|}{125 All Watersheds } & 125 & $\sqrt{ }$ & $\sqrt{ }$ & $\sqrt{ }$ & -- & -- & -- & -- & -- \\
\hline & $\begin{array}{l}\text { NRM-Distributed } \\
\text { (Xiang \& Demir, 2020) }\end{array}$ & \multicolumn{2}{|c|}{63 Downstream } & 63 & $\sqrt{ }$ & $\sqrt{ }$ & $\sqrt{ }$ & -- & -- & -- & -- & $\sqrt{ }$ \\
\hline \multirow{2}{*}{$\begin{array}{l}\text { Test 1, NRM- } \\
\text { Generalized } \\
\text { Model }\end{array}$} & $\begin{array}{l}\text { NRM-Generalized- } \\
\text { Baseline }\end{array}$ & \multicolumn{2}{|c|}{62 Upstream } & 1 & $\sqrt{ }$ & $\sqrt{ }$ & $\sqrt{ }$ & -- & -- & -- & -- & -- \\
\hline & NRM-Generalized & \multicolumn{2}{|c|}{62 Upstream } & 1 & $\sqrt{ }$ & $\sqrt{ }$ & $\sqrt{ }$ & $\sqrt{ }$ & $\sqrt{ }$ & $\sqrt{ }$ & $\sqrt{ }$ & -- \\
\hline \multirow{3}{*}{$\begin{array}{l}\text { Test 2, Spatial } \\
\text { Generalization } \\
\text { Test }\end{array}$} & \multirow{3}{*}{ NRM-Generalized } & \multirow{3}{*}{$\begin{array}{c}42 \\
\text { Upstream }\end{array}$} & 42 Upstream & \multirow{3}{*}{1} & \multirow{3}{*}{$\sqrt{ }$} & \multirow{3}{*}{$\sqrt{ }$} & \multirow{3}{*}{$\sqrt{ }$} & \multirow{3}{*}{$\sqrt{ }$} & \multirow{3}{*}{$\sqrt{ }$} & \multirow{3}{*}{$\sqrt{ }$} & \multirow{3}{*}{$\sqrt{ }$} & \multirow{3}{*}{--} \\
\hline & & & 20 Upstream & & & & & & & & & \\
\hline & & & $\begin{array}{c}18 \\
\text { Downstream } \\
\end{array}$ & & & & & & & & & \\
\hline \multirow{4}{*}{$\begin{array}{l}\text { Test } 3 \text {, Ablation } \\
\text { Study }\end{array}$} & Ablation 1 & \multicolumn{2}{|c|}{62 Upstream } & 1 & $\sqrt{ }$ & $\sqrt{ }$ & $\sqrt{ }$ & -- & $\sqrt{ }$ & $\sqrt{ }$ & $\sqrt{ }$ & -- \\
\hline & Ablation 2 & \multicolumn{2}{|c|}{62 Upstream } & 1 & $\sqrt{ }$ & $\sqrt{ }$ & $\sqrt{ }$ & $\sqrt{ }$ & -- & $\sqrt{ }$ & $\sqrt{ }$ & -- \\
\hline & Ablation 3 & \multicolumn{2}{|c|}{62 Upstream } & 1 & $\sqrt{ }$ & $\sqrt{ }$ & $\sqrt{ }$ & $\sqrt{ }$ & $\sqrt{ }$ & -- & $\sqrt{ }$ & -- \\
\hline & Ablation 4 & \multicolumn{2}{|c|}{62 Upstream } & 1 & $\sqrt{ }$ & $\sqrt{ }$ & $\sqrt{ }$ & $\sqrt{ }$ & $\sqrt{ }$ & $\sqrt{ }$ & -- & -- \\
\hline \multirow{4}{*}{$\begin{array}{l}\text { Test 4, NRM- } \\
\text { Generalized- } \\
\text { Distributed Model }\end{array}$} & \multirow{2}{*}{ NRM-Generalized } & \multicolumn{2}{|c|}{63 Downstream } & 1 & \multirow{2}{*}{$\sqrt{ }$} & \multirow{2}{*}{$\sqrt{ }$} & \multirow{2}{*}{$\sqrt{ }$} & \multirow{2}{*}{$\sqrt{ }$} & \multirow{2}{*}{$\sqrt{ }$} & \multirow{2}{*}{$\sqrt{ }$} & \multirow{2}{*}{$\sqrt{ }$} & \multirow{2}{*}{--} \\
\hline & & 125 All V & atersheds & 1 & & & & & & & & \\
\hline & NRM-Generalized- & 63 Dov & nstream & 1 & $\sqrt{ }$ & $\sqrt{ }$ & $\sqrt{ }$ & $\sqrt{ }$ & $\sqrt{ }$ & $\sqrt{ }$ & $\sqrt{ }$ & $\sqrt{ }$ \\
\hline & Distributed & 125 All V & atersheds & 1 & & & & & & & & \\
\hline
\end{tabular}




\section{Results and Discussions}

In this study, we reviewed two deep learning models, NRM-Generalized and NRMGeneralized-Distributed, and applied these models to different watersheds as shown in Table 4. The results of the NRM-Generalized model on 62 upstream watersheds (section 3.1) and untrained watersheds (section 3.2), are shown in the following sections. Section 3.3 shows the results of an ablation study. The results of NRM-Generalized-Distributed on 63 downstream and all 125 USGS gauges are shown in section 3.4. Additional evaluations, such as low- and high-flow; and real situations of limited rainfall data, are shown in section 3.5.

\subsection{NRM-Generalized on Upstream Watersheds}

Sixty-two (62) independent upstream Iowa watersheds with USGS streamflow gauge data in the study years are selected. The median values for the statistical metrics from 62 upstream stations of are shown in Figure 3. For upstream watersheds, the fraction of lead time over concentration time ranges from 0.063 (or $10^{-2.2}$ ) to 4 (or $10^{0.6}$ ) in log scale at a step of $10^{0.2}$. The longest hindcast window in our study is 120 hours with lead times ranging from 1 to 120 hours, the lead time over concentration time varies for different watersheds. Most of these are less than four.

These results show that the increase in lead time decreased the performance of all three benchmark models for both NSE and KGE. The temporal persistence model shown by the black line (Fig. 3) has a high performance at low lead time fraction because the median streamflow does not change significantly over several hours. However, the model's persistence performance decreased dramatically for both NSE and KGE when the lead time over concentration time increased. Different to the persistence, NRM displays a more stable performance for longer hindcast lead time over concentration time compared to the persistence model, and the median NSE reduced from 0.963 to 0.730 when the fraction of 
lead time over concentration time increased from 0.0063 to 4 . The last benchmark model, NRM-Generalized-Baseline is significantly worse than NRM in both metrics.

Our NRM-Generalized model on 62 upstream watersheds is shown in light blue (Fig. 3). Compared to the NRM and NRM-Generalized-Baseline, the NRM-Generalized model considered additional features including the area, time of concentration, average slope, and soil composition ratios for each watershed. We found that our generalized model had a better performance for 62 watersheds than NRM's 62 individual models did, based on the NSE. For the KGE, we found that the NRM-Generalized model had a slightly poorer performance for short-term hindcast but better performance for the long-term hindcast and overall performance than NRM.
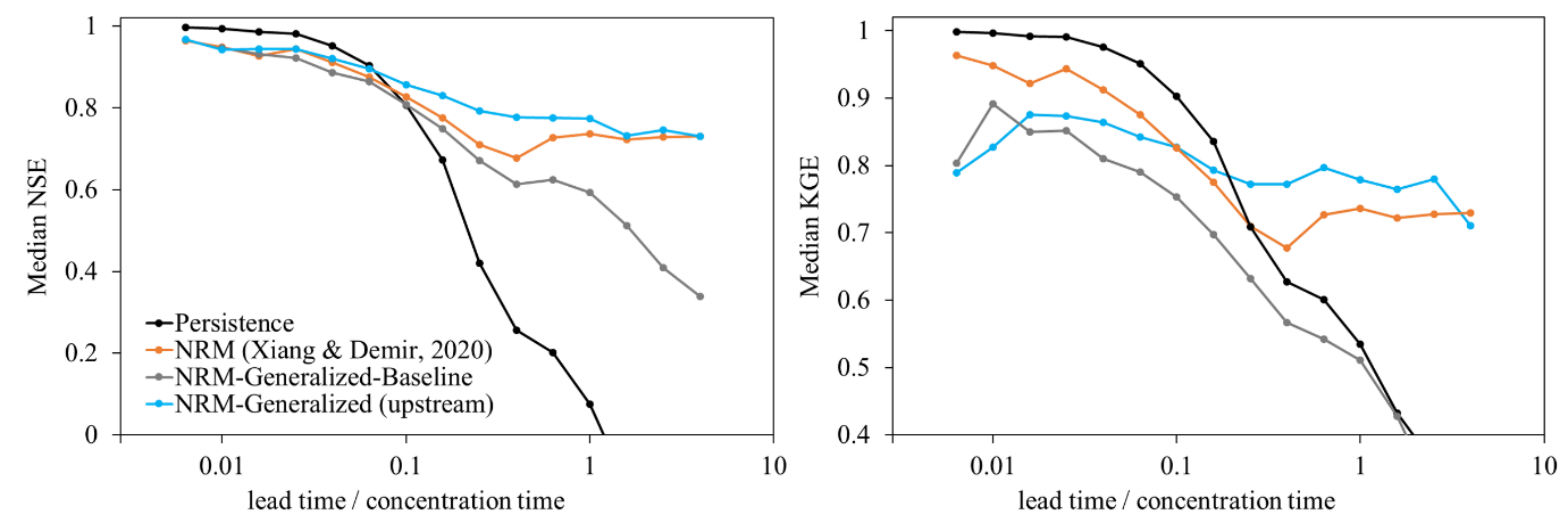

Figure 3. Median NSE (left) and KGE (right) values for 62 upstream watersheds using different models.

Overall, it is obvious that NRM-Generalized increased the model's performance significantly compared to NRM-Generalized-Baseline. This test successfully applied the generalized model on 62 independent watersheds in Iowa with a better median performance than 62 individual models. This is parallel to the results by Kratzert et al. (2018), which showed that a generalized model may perform better on multiple watersheds when those 
watersheds are similar. The success of NRM-Generalized also indicates that the rainfallrunoff behavior of watersheds can be effectively characterized by the features of slope, area, time of concentration, and soil types.

\subsection{Spatial Generalization Test}

In this test, the generalized model and baselines shown in Figure 4 were trained on 42 selected upstream watersheds using only data from water year 2012-2017. We then tested three different datasets, including 42 selected upstream watersheds, 20 untrained upstream watersheds, and 18 untrained downstream watersheds for water year 2018. The 20 untrained upstream watersheds are independent of the 42 upstream watersheds in the training dataset. The 18 downstream gauges are located downstream of these 42 watersheds; thus, they share parts of the same watershed area in the training dataset and are expected to have reasonably similar results.

Figures $4 \mathrm{a}$ and $4 \mathrm{~b}$ show that the NRM-Generalized-Baseline is a valid model for selected watersheds because the model has better performance than the runoff persistence. The NRM and NRM-Generalized models predict more accurately when the fraction of lead time over concentration time is more than 0.5 . The NRM-Generalized model trained on 42 watersheds has a slightly reduced median performance compared to NRM when the fraction of lead time over concentration time is more than 0.7 .

Figures $4 \mathrm{c}$ and $4 \mathrm{~d}$ show the model's performance on 20 untrained independent watersheds. As seen in Figs. 4a and 4b, NRM has the best model performance in all metrics. These watersheds have slightly reduced model performances for both NRM-GeneralizedBaseline and NRM-Generalized because the size of these 20 watersheds is in the range of the training dataset. With four additional features, NRM-Generalized has a better model performance than the baseline on NSE. 
Figures $4 \mathrm{e}$ and $4 \mathrm{f}$ show the model performance for 18 untrained downstream watersheds. As expected, NRM has the best model performance in both metrics. However, NRM-Generalized-Baseline shows much worse results in both metrics on these watersheds than other models with very high bias. For both NSE and KGE, the baseline model shows the same trend with worse results compared to the temporal persistence. By looking at the model simulation results in detail, we found that the baseline model overpredicted the streamflow in almost all downstream watersheds.

The results in Figs. $4 \mathrm{a}$ and $4 \mathrm{~b}$ for 42 training watersheds are consistent with the results in previous sections which indicates the model results are reasonable. This test in Figs. 4c and $4 \mathrm{~d}$ examined the spatial generalization ability by evaluating the generalized model on untrained watersheds of similar features. The proposed NRM-Generalized shows acceptable performance. This results in Figs. $4 \mathrm{e}$ and $4 \mathrm{f}$ indicate that the deep learning baseline model ascertained the fact that the increase in precipitation volume results in an increase in streamflow rate; however, the extensibility is poor without watershed features. Our NRMGeneralized model with watershed topological features has been successfully applied to these downstream watersheds with significantly better model performance than the baseline model. It is indicated from the results that the NRM-Generalized is an efficient regional model with acceptable spatial generalization ability that can be applied to untrained watersheds, both external independent watersheds and extended downstream watersheds, with a limited decrease in model performance. However, it needs to be noted that, when modeling these watersheds, the past 72 hours of streamflow data are still used for data assimilation. Therefore, this study cannot be applied to an ungauged watershed; however, it provides a simulation method for newly gauged watersheds. For example, in Iowa, Iowa Flood Center (IFC) has deployed nearly 300 stream level sensors in the past several years to measure the stream stage (Krajewski et al., 2017) and developed synthetic rating curves for those 
locations (Quintero et al., 2021). The generalized model proposed in this study can be applied to make simulations in these areas without relying on decades of historical data.
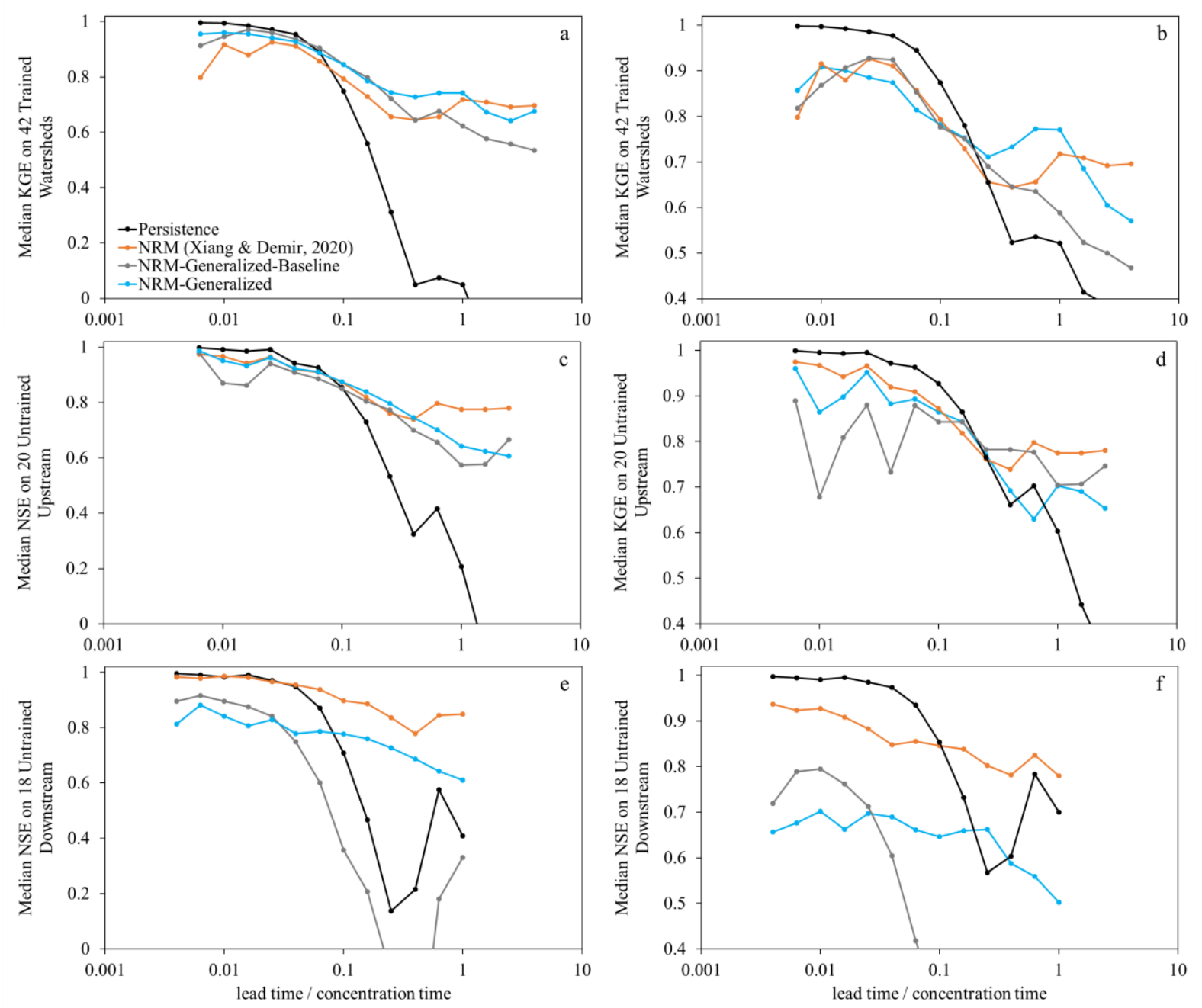

Figure 4. Median NSE and KGE among 42 trained watersheds (a, b), 20 untrained independent watersheds (c, d), and 18 untrained downstream watersheds (e, f) against the fraction of lead time over concentration time using different models.

\subsection{Ablation Study}

We conducted an ablation study to learn whether all four watershed features are necessary by removing one feature at a time. As shown in Table 5, the slope was removed in the ablation test 1 ; the area was removed in test 2 ; the time of concentration was removed in test 3 ; and 12 
soil type features were removed in test 4 . Because all models have a slow descending tendency toward the increase of lead time, the table only shows the median of 120-hr lead time modeling results.

The results in Table 5 show that the removal of any one feature will cause a decrease of NSE and KGE compared to NRM-Generalized. The ablation test 3 without the time of concentration has the least decrease of both NSE and KGE, which has least impact on performance. The ablation test 4 without the soil types has the worst NSE and KGE among four ablation tests, which indicates that the soil type is the most important parameter. Among all the generalized models, NRM-Generalized with all features has the highest NSE and KGE, which indicates that all four features are necessary and important.

Table 5. Median NSE and KGE among 62 upstream stations for the 120-hr lead time modeling using different models.

\begin{tabular}{cccccccccc}
\hline NRM Test Name & Precipitation & ET & Streamflow & Slope & Area & $\mathrm{T}_{\mathrm{c}}$ & Soil & NSE & KGE \\
\hline Persistence & & & $\sqrt{ }$ & & & & & -0.467 & 0.269 \\
NRM & $\sqrt{ }$ & $\sqrt{ }$ & $\sqrt{ }$ & & & & & 0.690 & 0.714 \\
NRM-Generalized-Baseline & $\sqrt{ }$ & $\sqrt{ }$ & $\sqrt{ }$ & & & & & 0.370 & 0.354 \\
NRM-Generalized & $\sqrt{ }$ & $\sqrt{ }$ & $\sqrt{ }$ & $\sqrt{ }$ & $\sqrt{ }$ & $\sqrt{ }$ & $\sqrt{ }$ & 0.723 & 0.734 \\
Ablation 1 & $\sqrt{ }$ & $\sqrt{ }$ & $\sqrt{ }$ & & $\sqrt{ }$ & $\sqrt{ }$ & $\sqrt{ }$ & 0.686 & 0.691 \\
Ablation 2 & $\sqrt{ }$ & $\sqrt{ }$ & $\sqrt{ }$ & $\sqrt{ }$ & & $\sqrt{ }$ & $\sqrt{ }$ & 0.704 & 0.658 \\
Ablation 3 & $\sqrt{ }$ & $\sqrt{ }$ & $\sqrt{ }$ & $\sqrt{ }$ & $\sqrt{ }$ & & $\sqrt{ }$ & 0.712 & 0.686 \\
Ablation 4 & $\sqrt{ }$ & $\sqrt{ }$ & $\sqrt{ }$ & $\sqrt{ }$ & $\sqrt{ }$ & $\sqrt{ }$ & & 0.650 & 0.629 \\
\hline
\end{tabular}

Table 6 shows a correlation heat map with the values of the $\mathrm{r}^{2}$ correlation coefficient for the 120-hr lead time modeling NSE along with the input feature values for each model. This figure shows only four major soil types in Iowa, although the model considers all 12 solid types. The temporal persistence model shows a high correlation of model NSE to the time of concentration and area, which is consistent with other studies (Ghimire and Krajewski, 2020) showing that in large watersheds with higher baseflow yields, it is more likely to get a better persistence result. The NRM-Distributed-Baseline does not include any of these input features in the modeling, and it has the $\mathrm{r}^{2}$ higher than 0.1 for most of the 
features. In contrast, the results of NRM show a very low correlation to the mean precipitation, streamflow, $\mathrm{T}_{\mathrm{c}}$, area, and soil types. Although NRM did not use any of these features as input, it is not biased as expected because NRM trained one model for each watershed.

The NRM-Distributed model proposed in this study shows correlations lower than 0.1 between model efficiency and most of features, which further demonstrates that it is a wellgeneralized model that does not show significant bias toward any watershed topological feature. Ablation tests 1, 3, and 4 show poorer results than NRM-Distributed with more than one values higher than 0.1 . We also found that the deep learning models are relatively robust against the input features, and removing any single feature in this test will cause no certain bias. For example, ablation 2 does not consider the watershed area feature, but it still not biased on areas.

In an earlier study, Kratzert et al. (2019) suggested that meteorological data (e.g., mean precipitation and aridity) are the most important factor in the sensitivity analysis of their hydrologic model. This is possible because baseline models such as persistence and NRM-Distributed-Baseline have a high correlation between meteorological data (e.g., mean precipitation $\mathrm{P}_{\text {mean }}$ and mean streamflow $\mathrm{Q}_{\text {mean }}$ ) and model performance. However, our models do not show bias for mean precipitation. We suggest that the hydrological behavior is more related to topological features (e.g., area, $\mathrm{T}_{\mathrm{c}}$, soil types, and slope) in the streamflow modeling. Watershed-scale meteorological data may not have a significant impact because the lead time is short and the precipitation data are already input features, which can be captured by deep learning models. 
Table 6. Squared correlation coefficient $\left(\mathrm{r}^{2}\right)$ between 120-hr lead time model modeling NSE and input features among 62 watersheds.

\begin{tabular}{|l|c|c|c|c|c|c|c|c|c|}
\hline & \multirow{2}{*}{$\mathrm{P}_{\text {mean }}$} & $\mathrm{Q}_{\text {mean }}$ & $\mathrm{T}_{\mathrm{c}}$ & Area & Slope & Loam & Silt & $\begin{array}{c}\text { Sandy } \\
\text { clay loam }\end{array}$ & $\begin{array}{c}\text { Silty clay } \\
\text { loam }\end{array}$ \\
\hline Persistence & 0.44 & 0.43 & 0.46 & 0.47 & 0.05 & 0.10 & 0.29 & 0.33 & 0.01 \\
\hline $\begin{array}{l}\text { NRM (Xiang \& } \\
\text { Demir, 2020) }\end{array}$ & 0.00 & 0.02 & 0.00 & 0.00 & 0.12 & 0.08 & 0.04 & 0.10 & 0.10 \\
\hline $\begin{array}{l}\text { NRM-Distributed- } \\
\text { Baseline }\end{array}$ & 0.11 & 0.11 & 0.16 & 0.10 & 0.07 & 0.04 & 0.11 & 0.02 & 0.01 \\
\hline NRM-Distributed & 0.06 & 0.09 & 0.06 & 0.05 & 0.03 & 0.08 & 0.12 & 0.07 & 0.00 \\
\hline Ablation 1 & 0.17 & 0.19 & 0.19 & 0.15 & 0.01 & 0.10 & 0.19 & 0.07 & 0.00 \\
\hline Ablation 2 & 0.04 & 0.07 & 0.05 & 0.04 & 0.01 & 0.09 & 0.13 & 0.08 & 0.01 \\
\hline Ablation 3 & 0.10 & 0.12 & 0.15 & 0.09 & 0.02 & 0.10 & 0.21 & 0.07 & 0.00 \\
\hline Ablation 4 & 0.21 & 0.24 & 0.25 & 0.20 & 0.00 & 0.14 & 0.21 & 0.13 & 0.01 \\
\hline
\end{tabular}

\subsection{NRM-Generalized-Distributed on Downstream and All Watersheds}

In addition to 62 upstream gauges, there are 63 USGS gauges located at the downstream of the gauges. We applied the NRM-Generalized model on 63 downstream gauges in this test first. The NSE results of different models are shown in Figure 5. For downstream watersheds, the figure shows the fraction of lead time over concentration time ranges from 0.004 to 1 in $\log$ scale. The reason why the maximum scale is 1 in Figure 5 rather than 4 in Figure 3 is the downstream watersheds normally have larger concentration time and their median concentration time is 99 hours as shown in Table 3.

When the fraction of lead time over concentration time is 1 , the median NSE is 0.826 in the NRM-Generalized model training on 63 downstream watersheds. As shown in Figure 5, results of NRM-Generalized are better than NRM in both NSE and KGE at all lead hours, which is even better than the results on 62 upstream watersheds. The main difference here is these downstream watersheds are not independent and many of them are sharing the same areas. The performance increase from NRM to NRM-Generalized can be explained by the information among different watersheds that are well utilized since they have higher similarities. 
After the implementation of the distributed model, the performance of NRMGeneralized-Distributed significantly increased compared to the NRM-Generalized on both metrics. NRM-Generalized-Distributed models have the median NSE of 0.873 when the fraction of lead time over concentration time is 1 . It needs to be noticed that, since the distributed model used the upstream streamflow model output data, accurate upstream streamflow for the future 120 hours is used in the training. And in the evaluation and testing, the generalized model is executed sequentially for each watershed based on the stream network, and the next 120 hours upstream model output data from our models are used as input. Thus, there is no data leaking issue in distributed models and the NRM-GeneralizedDistributed is proved to be effective compared to the NRM-Distributed baseline with a little and acceptable sacrifice on the NSE but a slightly better KGE performance. This result confirmed that the physical features included in the generalized models successfully characterized the behaviors. And this further demonstrated the findings of including watersheds with similar behaviors in the generalized model can provide better results. Our proposed distributed generalized model is effective in reducing the number of parameters with a limited sacrifice of model performance.
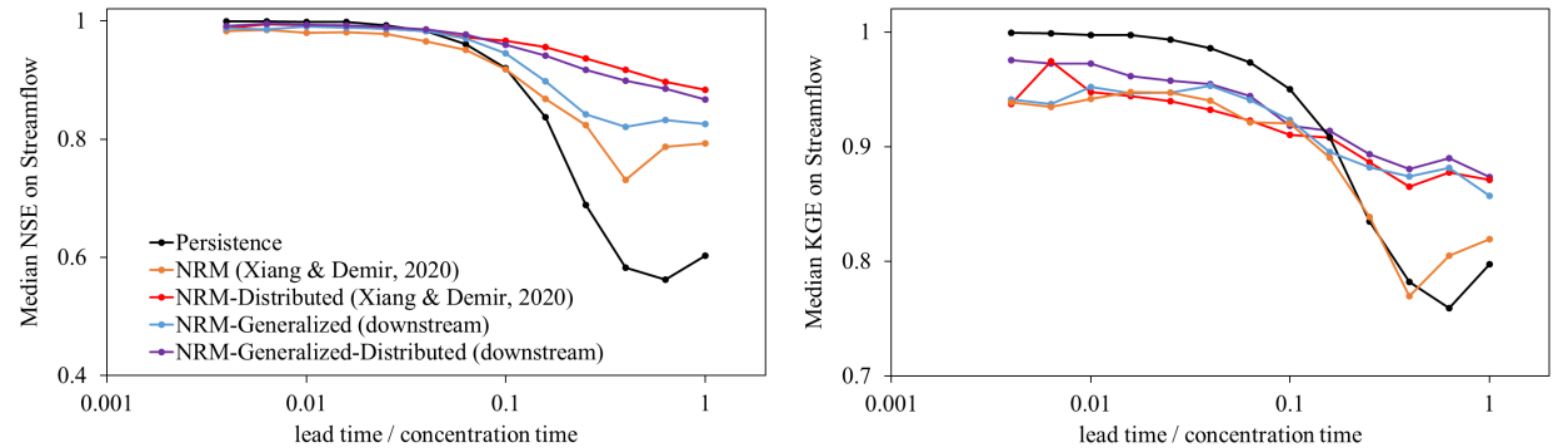

Figure 5. Median NSE (left) and KGE (right) values for 63 downstream watersheds using different models. 
In this test, we developed two models, with and without distributed structure, to include all 125 watersheds in one model as our final tests. The results are shown in Figure 6. It shows that the distributed model promoted the model performance as well. This is expected since our studies simplified three-dimensional spatial-temporal precipitation data into onedimensional temporal data by spatial averaging for each watershed. As shown in Table 3, the upstream and downstream watershed size varies significantly. The distributed structure considers the sub-watersheds only, which significantly decreased the median watersheds' sizes from 1,675 $\mathrm{km}^{2}$ to $947 \mathrm{~km}^{2}$, and the median travel time from 53 hours to 26 hours in the modeling. Thus, the models with distributed structures can reduce the errors caused by the uneven spatial distribution of precipitation since the sub-watershed boundaries are used.

In contrast, without a distributed structure, the variances of slope and soil types may be neglected when the watershed sizes are too large. Since distributed models have a much smaller area and time of concentration, the features of the slope and soil types can characterize these sub-watersheds more accurately and improve the model performance. When we compare the results of NRM-Generalized (upstream) + NRM-Generalized (downstream) and NRM-Generalized (125 all), it indicates that two regional models could be better than one model when some watershed features (i.e., area) are highly heterogeneous in the dataset. And we concluded that the regional generalized models can provide better results only when all features are effectively pre-treated and in a reasonable variance. Thus, we used our best model, NRM-Generalized for upstream and NRM-Generalized-Distributed for downstream, in our further analysis.

\subsection{Overview of Generalized Models}

Figure 7 shows the 120-hr lead time simulation NSE and KGE distribution against the concentration time, area, and slope among 125 watersheds in the test year. We only compared 
the best models with and without the generalization. Thus, we are comparing the overall performances of the deep learning model in Iowa using 125 watershed models and 2 generalized models. For the 120-hr lead time simulations, the overall median NSE is 0.742 and 0.776 in NRM and NRM-Generalized models, respectively, using distributed structures. This corresponds to the results in previous sections. Although the median NSE of the generalized model is better than the individual models trained on each watershed, our generalized model has lower performance at both NSE and KGE metrics for smaller watersheds with less concentration time.
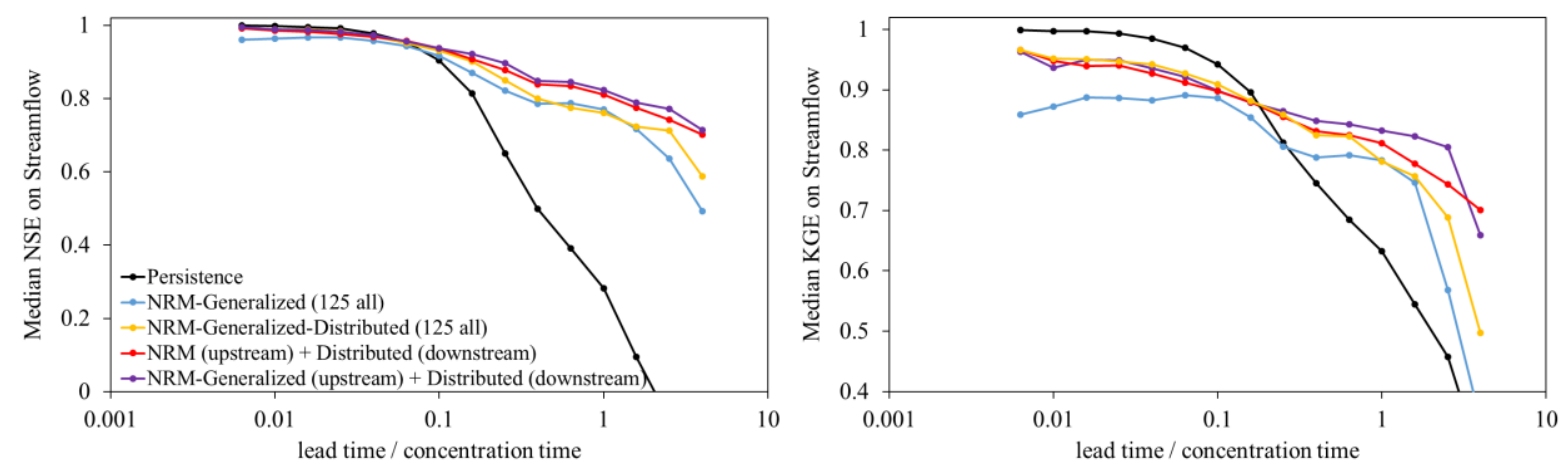

Figure 6. Median NSE (left) and KGE (right) values for all 125 watersheds using different models. 

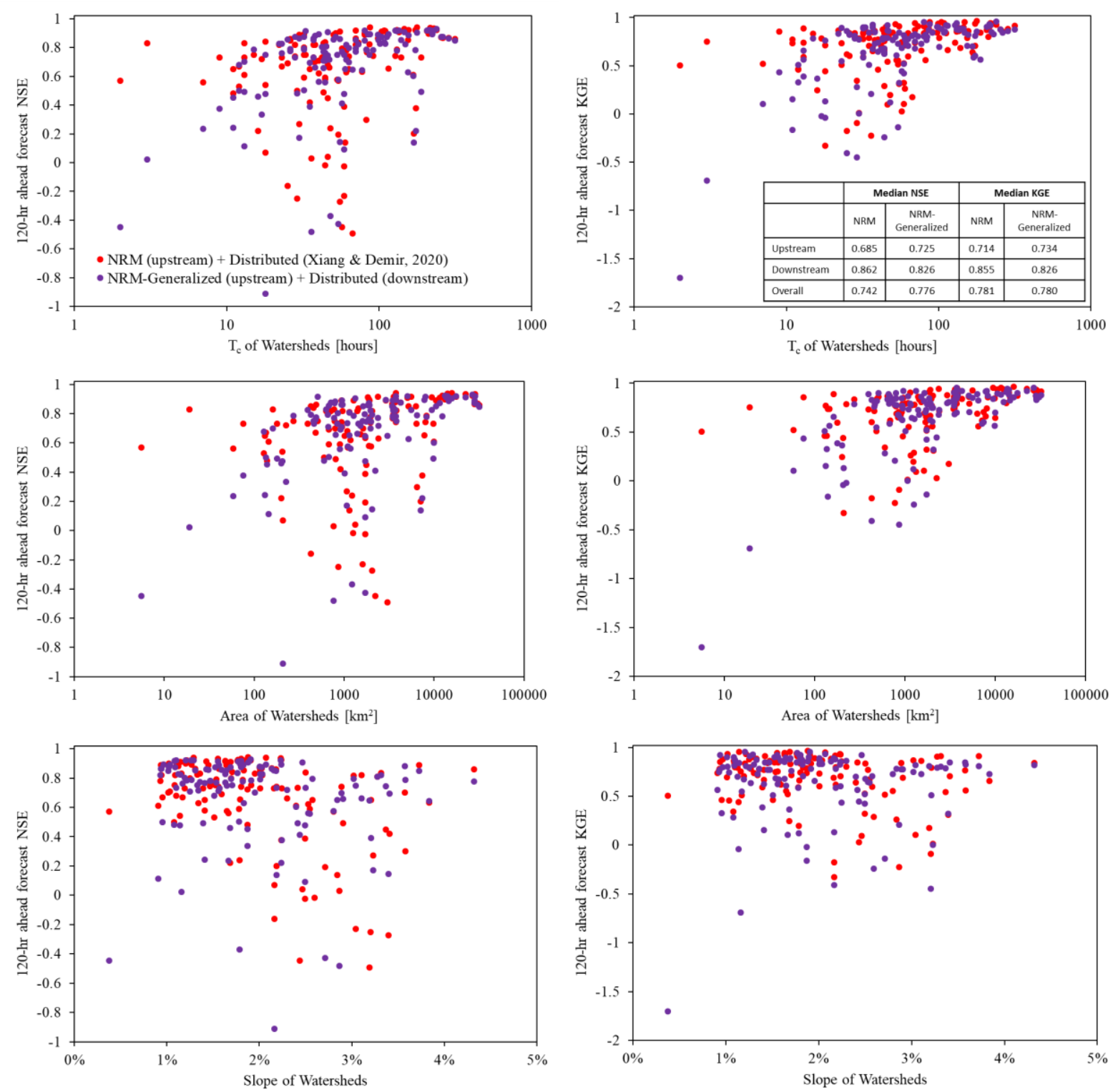

Figure 7. The 120-hr lead time simulation of NSE and KGE distribution against the concentration time, area, and slope among 125 watersheds in the test year.

In addition, the watersheds with the largest and smallest mean slopes have significantly reduced performance in the generalized model as well. This indicates that the generalized model may not perform as well on extreme cases as training one model for each watershed. This is a common issue in the model generalization because these watersheds are underrepresented in the dataset. This indicates that the proposed generalized model could be 
more stable on ordinary watersheds for an average situation rather than special watersheds with extreme features.

\section{Conclusion}

In this study, we developed two generalized deep learning-based rainfall-runoff models, NRM-Generalized and NRM-Generalized-Simulcast. The models are designed to predict the next 120 hours of streamflow using observed rainfall, a "perfect" rainfall forecast, observed runoff, evapotranspiration, watershed area, time of concentration, average slope, and the proportion of 12 soil types. The study successfully characterized the watershed features and trained on data from multiple watersheds in a single model without reducing median model accuracy in five comprehensive tests.

In the first test, three benchmark models (temporal persistence, NRM, NRMGeneralized-Baseline) and the proposed NRM-Generalized model are developed by training on 62 upstream watersheds in Iowa. The proposed NRM-Generalized model has the median 120-hr lead time prediction NSE and KGE higher than the NRM-Generalized-Baseline and temporal persistence. NRM-Generalized model also has similar or better performance than the NRM models. This indicates that additional features including slope, area, time of concentration, and soil types, contributed to effective characterization of the rainfall-runoff behavior among different watersheds.

In the spatial generalization test, we created a dataset containing data from 42 watersheds in training and applied the trained model on 20 untrained upstream watersheds and 18 untrained downstream watersheds. The results show that the model provides comparable results to previous models and can work on both external independent watersheds and extended downstream watersheds with a limited decrease in accuracy. This further demonstrated the generalizability and transferability of the model proposed in this study. 
Theoretically, the trained model can be applied to any new gauges in Iowa without training, at acceptable accuracy. More data from additional gauges may increase the accuracy in future studies.

In the ablation study, we confirmed that all the features included in the generalized model are contributing to the performance. The correlation analysis shows that including these four watershed features helps to reduce the bias among these features compared to the NRM-Generalized-Baseline model, which has no watershed feature.

After introducing the distributed model structure, we tested the NRM-GeneralizedDistributed model on 63 downstream watersheds. Results show that our proposed distributed generalized model is effective and has a limited sacrifice of model performance compared to the baselines by execution sequentially for each watershed based on the stream network. We also compared the performance of the NRM-Generalized-Distributed as a single model on all 125 watersheds to the results from two regional models, NRM-Generalization (62 upstream) and NRM-Generalization (63 downstream). Two regional models outperformed the single model. This might be due to some watershed features (i.e., area) being highly heterogeneous in the dataset. We concluded that the regional generalized models can provide better results only when all features are effectively pre-treated and in a reasonable variance.

In the final overview, this study shows that our generalized model could be more stable on ordinary watersheds at an average situation rather than special watersheds with extreme features. Our generalized model may also underperform on small watersheds and at low flows. Our results also emphasize the importance of accurate precipitation forecast input for the deep learning models for operational real-time applications. These are some of the limitations for the generalized model using deep learning.

This study successfully developed a generalized model, NRM-GeneralizedDistributed, using a standard deep learning library with watershed features of the area, time 
of concentration, average slope, and proportions of 12 soil types. Compared to our previous best performing distributed model (NRM-Distributed), which trained one model for each watershed, the proposed generalized model shows a better performance on the median of 125 USGS streamflow gauges at the lead time of 120 hours with training only two regional models.

Researchers of deep learning in hydrology and water resources have increased significantly in the past several years (Sit et al., 2020), but there are limited considerations on physical features and processes. As shown in this study, deep learning models considering watershed-scale physical features and semi-distributed structures can work on multiple watersheds using regional models with limited sacrifice of accuracy. We reiterate our call to deep learning studies in hydrology to include more domain knowledge and physical features in the future.

\section{Acknowledgments}

The work reported in this study was made possible by the support of members of the Iowa Flood Center and the Department of Civil and Environmental Engineering at the University of Iowa.

\section{References}

Abobakr Yahya, A. S., Ahmed, A. N., Binti Othman, F., Ibrahim, R. K., Afan, H. A., ElShafie, A., ... \& Elshafie, A. (2019). Water quality prediction model based support vector machine model for Ungauged River catchment under dual scenarios. Water, 11(6), 1231.

Addor, N., Newman, A. J., Mizukami, N., \& Clark, M. P. (2017). The CAMELS data set: catchment attributes and meteorology for large-sample studies. Hydrology and Earth System Sciences, 21(10), 5293-5313.

Agliamzanov, R., Sit, M., \& Demir, I. (2020). Hydrology@ Home: a distributed volunteer computing framework for hydrological research and applications. Journal of Hydroinformatics, 22(2), 235-248.

Chang, F. J., Tsai, Y. H., Chen, P. A., Coynel, A., \& Vachaud, G. (2015). Modeling water quality in an urban river using hydrological factors-Data driven approaches. Journal of environmental management, 151, 87-96. 
Chen, Z., Zhu, Z., Jiang, H., \& Sun, S. (2020). Estimating daily reference evapotranspiration based on limited meteorological data using deep learning and classical machine learning methods. Journal of Hydrology, 591, 125286.

Chu, H., Wei, J., \& Wu, W. (2020). Streamflow prediction using LASSO-FCM-DBN approach based on hydro-meteorological condition classification. Journal of Hydrology, 580, 124253.

Demir, I., \& Szczepanek, R. (2017). Optimization of river network representation data models for web-based systems. Earth and Space Science, 4(6), 336-347.

Ebert-Uphoff, I., Thompson, D. R., Demir, I., Gel, Y. R., Karpatne, A., Guereque, M., ... \& Smyth, P. (2017, September). A vision for the development of benchmarks to bridge geoscience and data science. In 17th International Workshop on Climate Informatics.

Fang, K., \& Shen, C. (2020). Near-real-time forecast of satellite-based soil moisture using long short-term memory with an adaptive data integration kernel. Journal of Hydrometeorology, 21(3), 399-413.

Faruk, D. Ö. (2010). A hybrid neural network and ARIMA model for water quality time series prediction. Engineering applications of artificial intelligence, 23(4), 586-594.

Feng, D., Fang, K., \& Shen, C. (2020). Enhancing streamflow forecast and extracting insights using long-short term memory networks with data integration at continental scales. Water Resources Research, 56(9), e2019WR026793.

Ghimire, G. R., \& Krajewski, W. F. (2020). Exploring persistence in streamflow forecasting. JAWRA Journal of the American Water Resources Association, 56(3), 542550.

Gilles, D., Young, N., Schroeder, H., Piotrowski, J., \& Chang, Y. J. (2012). Inundation mapping initiatives of the Iowa Flood Center: Statewide coverage and detailed urban flooding analysis. Water, 4(1), 85-106.

Granata, F., Gargano, R., \& De Marinis, G. (2016). Support vector regression for rainfallrunoff modeling in urban drainage: A comparison with the EPA's storm water management model. Water, 8(3), 69.

Gupta, H. V., Kling, H., Yilmaz, K. K., \& Martinez, G. F. (2009). Decomposition of the mean squared error and NSE performance criteria: Implications for improving hydrological modelling. Journal of hydrology, 377(1-2), 80-91.

Hu, R., Fang, F., Pain, C. C., \& Navon, I. M. (2019). Rapid spatio-temporal flood prediction and uncertainty quantification using a deep learning method. Journal of Hydrology, 575, 911-920.

Kokkonen, T. S., Jakeman, A. J., Young, P. C., \& Koivusalo, H. J. (2003). Predicting daily flows in ungauged catchments: model regionalization from catchment descriptors at the Coweeta Hydrologic Laboratory, North Carolina. Hydrological processes, 17(11), 22192238.

Krajewski, W. F., Ceynar, D., Demir, I., Goska, R., Kruger, A., Langel, C., ... \& Young, N. C. (2017). Real-time flood forecasting and information system for the state of Iowa. Bulletin of the American Meteorological Society, 98(3), 539-554.

Krajewski, W.F., Ghimire, G.R. and F. Quintero, Streamflow forecasting without models, Journal of Hydrometeorology, 21(8), 1689-1704, 2020.

Kratzert, F., Klotz, D., Brenner, C., Schulz, K., \& Herrnegger, M. (2018). Rainfall-runoff modelling using long short-term memory (LSTM) networks. Hydrology and Earth System Sciences, 22(11), 6005-6022.

Kratzert, F., Klotz, D., Shalev, G., Klambauer, G., Hochreiter, S., \& Nearing, G. (2019). Towards learning universal, regional, and local hydrological behaviors via machine learning applied to large-sample datasets. Hydrology and Earth System Sciences, 23(12), 5089-5110. 
Kruger, A., Krajewski, W. F., Niemeier, J. J., Ceynar, D. L., \& Goska, R. (2016). Bridgemounted river stage sensors (BMRSS). IEEE Access, 4, 8948-8966.

Lee, T., Shin, J. Y., Kim, J. S., \& Singh, V. P. (2020). Stochastic simulation on reproducing long-term memory of hydroclimatological variables using deep learning model. Journal of Hydrology, 582, 124540.

Li, K., Wan, D., Zhu, Y., Yao, C., Yu, Y., Si, C., \& Ruan, X. (2020). The applicability of ASCS_LSTM_ATT model for water level prediction in small-and medium-sized basins in China. Journal of Hydroinformatics, 22(6), 1693-1717.

Lin, Y., 2011. GCIP/EOP Surface: Precipitation NCEP/EMC 4KM Gridded Data (GRIB) Stage IV Data. Version 1.0. UCAR/NCAR - Earth Obs. Lab. https://doi.org/https://doi.org/10.5065/D6PG1QDD

Liu, Y., Qin, H., Zhang, Z., Yao, L., Wang, Y., Li, J., ... \& Zhou, J. (2019). Deriving reservoir operation rule based on Bayesian deep learning method considering multiple uncertainties. Journal of Hydrology, 579, 124207.

Ni, L., Wang, D., Singh, V. P., Wu, J., Wang, Y., Tao, Y., \& Zhang, J. (2020). Streamflow and rainfall forecasting by two long short-term memory-based models. Journal of Hydrology, 583, 124296.

Perez, G., Mantilla, R., \& Krajewski, W. F. (2018). Estimation of Historical-Annual and Historical-Monthly Scale-Invariant Flow Duration Curves with Implementation for Iowa. Journal of Hydrologic Engineering, 23(12), 05018021.

Prieto, C., Le Vine, N., Kavetski, D., García, E., \& Medina, R. (2019). Flow prediction in ungauged catchments using probabilistic random forests regionalization and new statistical adequacy tests. Water Resources Research, 55(5), 4364-4392.

Qian, L., Li, J., Liu, C., Tao, J., \& Chen, F. (2020). River flow sequence feature extraction and prediction using an enhanced sparse autoencoder. Journal of Hydroinformatics, 22(5), 1391-1409.

Quintero, F., W.F. Krajewski, M. Muste, M. Rojas, G. Perez, S.J. Johnson, A.N. Anderson, T.J. Honemuller, W. Cappuccio, and J. Zogg, Development of synthetic rating curves: A case study in Iowa, Journal of Hydrologic Engineering, 26(1), 2021.

Quintero, F., Krajewski, W. F., Seo, B. C., \& Mantilla, R. (2020). Improvement and evaluation of the Iowa Flood Center Hillslope Link Model (HLM) by calibration-free approach. Journal of Hydrology, 584, 124686.

Quintero, F., Krajewski, W. F., \& Rojas, M. (2020). A flood potential index for effective communication of streamflow forecasts at ungauged communities. Journal of Hydrometeorology, 21(4), 807-814.

Razavi, T., \& Coulibaly, P. (2013). Streamflow prediction in ungauged basins: review of regionalization methods. Journal of hydrologic engineering, 18(8), 958-975.

S Ha, W., R Diak, G., \& F Krajewski, W. (2020). Estimating Near Real-Time Hourly Evapotranspiration Using Numerical Weather Prediction Model Output and GOES Remote Sensing Data in Iowa. Remote Sensing, 12(14), 2337.

Seo, B. C., \& Krajewski, W. F. (2020). Statewide real-time quantitative precipitation estimation using weather radar and NWP model analysis: Algorithm description and product evaluation. Environmental Modelling \& Software, 132, 104791.

Seo, B. C., Keem, M., Hammond, R., Demir, I., \& Krajewski, W. F. (2019). A pilot infrastructure for searching rainfall metadata and generating rainfall product using the big data of NEXRAD. Environmental modelling \& software, 117, 69-75.

Sarkar, A., Zhang, J., Lu, C., \& Jannesari, A. (2020). HydroDeep--A Knowledge Guided Deep Neural Network for Geo-Spatiotemporal Data Analysis. arXiv preprint arXiv:2010.04328. 
Sermet, Y., \& Demir, I. (2019). Flood action VR: a virtual reality framework for disaster awareness and emergency response training. In ACM SIGGRAPH 2019 Posters (pp. 12).

Sermet, Y., Demir, I., \& Muste, M. (2020). A serious gaming framework for decision support on hydrological hazards. Science of The Total Environment, 728, 138895.

Sermet, Y., Villanueva, P., Sit, M. A., \& Demir, I. (2020). Crowdsourced approaches for stage measurements at ungauged locations using smartphones. Hydrological Sciences Journal, 65(5), 813-822.

Sit, M., \& Demir, I. (2019). Decentralized flood forecasting using deep neural networks. arXiv preprint arXiv:1902.02308.

Sit, M., Demiray, B. Z., Xiang, Z., Ewing, G. J., Sermet, Y., \& Demir, I. (2020). A comprehensive review of deep learning applications in hydrology and water resources. Water Science and Technology, 82(12), 2635-2670.

Sivapalan, M. (2003). Prediction in ungauged basins: a grand challenge for theoretical hydrology. Hydrological processes, 17(15), 3163-3170.

Van, S. P., Le, H. M., Thanh, D. V., Dang, T. D., Loc, H. H., \& Anh, D. T. (2020). Deep learning convolutional neural network in rainfall-runoff modelling. Journal of Hydroinformatics, 22(3), 541-561.

Wang, N., Zhang, D., Chang, H., \& Li, H. (2020). Deep learning of subsurface flow via theory-guided neural network. Journal of Hydrology, 584, 124700.

Xiang, Z., \& Demir, I. (2020). Distributed long-term hourly streamflow predictions using deep learning-A case study for State of Iowa. Environmental Modelling \& Software, 131, 104761.

Xiang, Z., Yan, J., \& Demir, I. (2020). A rainfall-runoff model with LSTM-based sequenceto-sequence learning. Water resources research, 56(1), e2019WR025326.

Xu, H., Windsor, M., Muste, M., \& Demir, I. (2020). A web-based decision support system for collaborative mitigation of multiple water-related hazards using serious gaming. Journal of environmental management, 255, 109887.

Yildirim, E., \& Demir, I. (2019). An integrated web framework for HAZUS-MH flood loss estimation analysis. Natural Hazards, 99(1), 275-286.

Yu, X., Cui, T., Sreekanth, J., Mangeon, S., Doble, R., Xin, P., ... \& Gilfedder, M. (2020). Deep learning emulators for groundwater contaminant transport modelling. Journal of Hydrology, 590, 125351.

Yue, Z., Ai, P., Xiong, C., Hong, M., \& Song, Y. (2020). Mid-to long-term runoff prediction by combining the deep belief network and partial least-squares regression. Journal of Hydroinformatics, 22(5), 1283-1305.

Zhou, Y. (2020). Real-time probabilistic forecasting of river water quality under data missing situation: Deep learning plus post-processing techniques. Journal of Hydrology, 589, 125164. 


\section{Appendix A}

Figure A1 shows the statistics for the overall results and performance at low flows (e.g., the observed flow rates are lower than the median test year flow rate $\mathrm{Q}_{50}$ ) and high flows (e.g., the observed flow rates are higher than $Q_{50}$ ) in the test year using our final models in four gauged watersheds. Watersheds 1 and 3 are relatively small, with a concentration time of 28 and 32 hours. Watersheds 2 and 4 are relatively large, with a concentration time of 101 and 148 hours. Watersheds 1 and 2 are upstream gauges using NRM-Generalized; watersheds 3 and 4 are the downstream of 1 and 2, respectively, using NRM-Generalized-Distributed. In watersheds 1 and 3, the figure shows that the model performance at high flow and low flow are both worse than the overall results, which indicates that the good performance overall is the result of over-prediction of low flow and under-prediction of high flow. In watershed 2, there is also a significant bias between the performance of high flow and low flow. The partial bias could be a problem and can be addressed through a better designed loss function in the deep learning models. This could be resolved in a future study. 

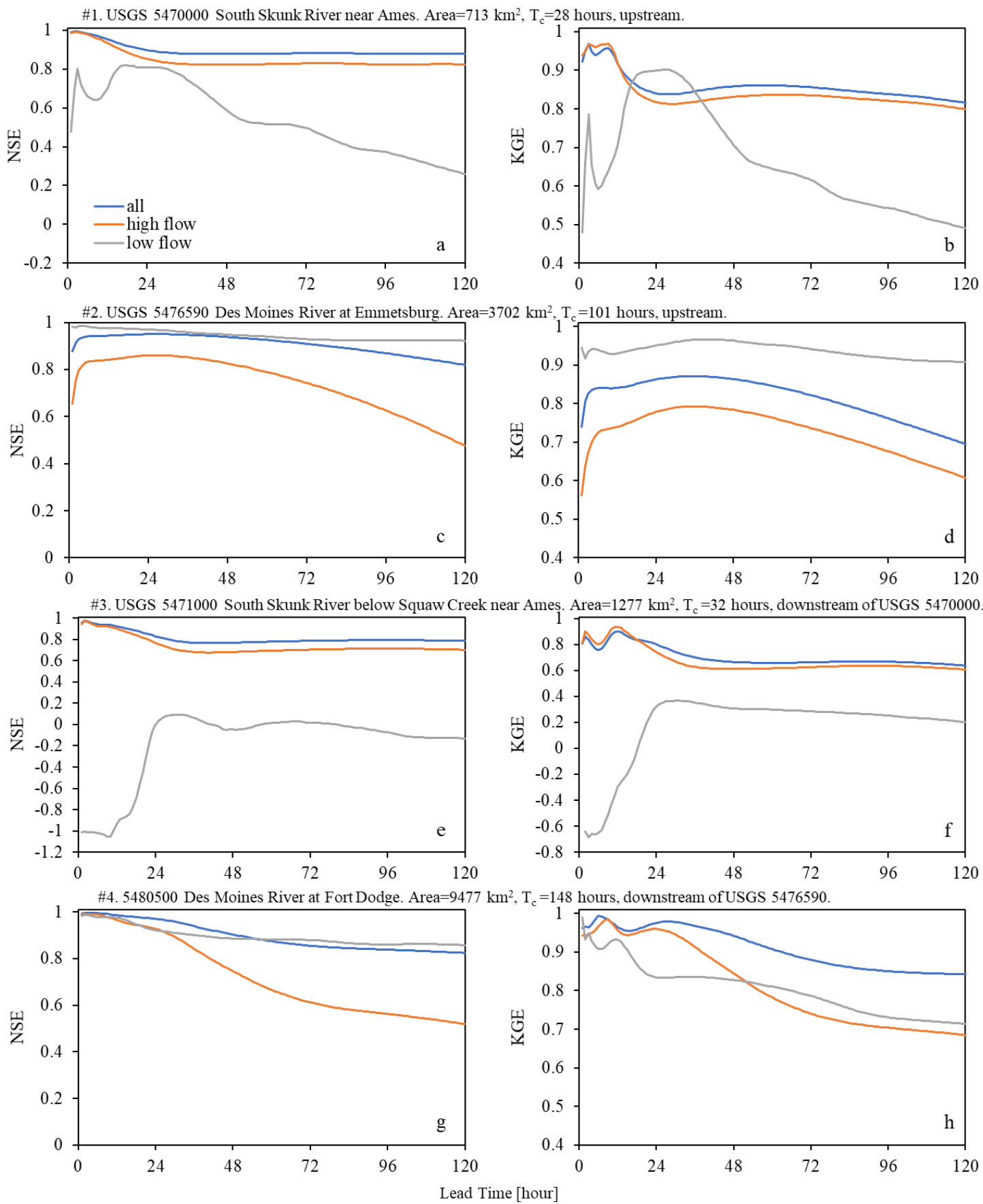

Figure A1. The NSE and KGE final modeling results for four selected USGS-gauged watersheds, NRM-Generalized for upstream watersheds and NRM-Generalized-Distributed for downstream watersheds, at all lead times. Q50 represents the median flow rate in each watershed in the test year. 

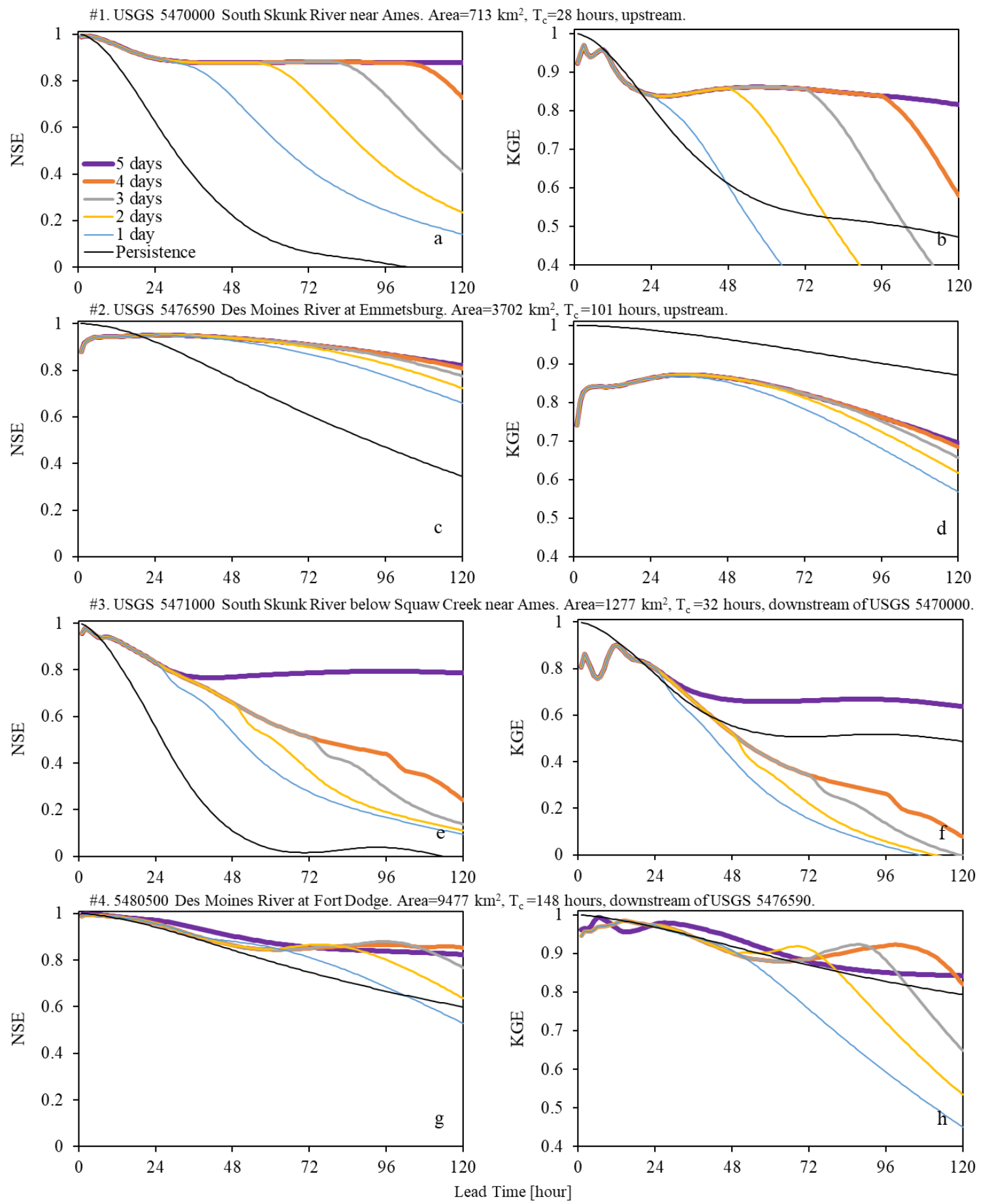

Figure A2. The NSE and KGE of the final model results for four selected USGS-gauged watersheds, NRM-Generalized for upstream watersheds and NRM-Generalized-Distributed 
for downstream watersheds, at all lead times with 1,2,3,4, and 5 days precipitation as input. The temporal persistence is used as a reference.

All the results in this study focus on five-day predictions using accurate hourly precipitations. Since current meteorological forecasts can only provide accurate short-range hourly precipitation predictions (i.e., HRRRv3 (High-Resolution Rapid Refresh) version 3), an hourly precipitation forecast product can provide at most a 36-hour precipitation forecast. Our study tested the modeling performance under limited precipitation in a potential real-time application of our models. As shown by the purple lines in Fig. A2, our model has a stable performance in all metrics for five days of rainfall because it assumes that the next 120 hours of accurate precipitation data are known. By assuming the hourly precipitation is 0 after 24 , 48, 72, and 96 hours, we have four additional models that only know the future rainfall for 4 , 3, 2, and 1 days respectively; the results are shown in Fig. A2. Since the long-term hourly precipitation data is set to 0 after different timestamps in these tests, the long-range model accuracies after the timestamp decrease dramatically in watersheds 1 and 3 . This is reasonable because precipitation is the key driving force of the streamflow; these two stations have a very small concentration time. Watersheds 2 and 4 are relatively large, with concentration times of 101 hours and 148 hours, respectively. The decrease in model performance is very limited compared to stations 1 and 3 in our predictions at most 120 hours. It is also obvious that the model accuracy curves overlap if the rainfall is known. The model performance only decreases after the precipitation data sets to zero because our model is designed to predict streamflow hour by hour in the NRM architecture. This indicates that the deep learning model using time series architectures is reliable for short-time predictions even with limited accurate long-term precipitation data. 